\title{
Complication analysis in nitinol stent-assisted embolization of 486 intracranial aneurysms
}

\author{
Andrew Kelly Johnson, MD, ${ }^{1}$ Stephan A. Munich, MD, ${ }^{1}$ Lee A. Tan, MD, ${ }^{1}$ \\ Daniel Mark Heiferman, MD, ${ }^{2}$ Kiffon Marie Keigher, APN, ${ }^{1}$ and Demetrius Klee Lopes, MD' \\ 1Department of Neurosurgery, Rush University Medical Center, Chicago; and 2Department of Neurological Surgery, Loyola \\ University Medical Center, Maywood, Illinois
}

\begin{abstract}
OBJECT Stent-assisted embolization (SAE) has broadened the scope of endovascular cerebral aneurysm treatment. The risks associated with stent selection and configuration are poorly defined. In this study, the authors aimed to characterize the risk factors that contribute to complications in SAE of intracranial aneurysms.
\end{abstract}

\begin{abstract}
METHODS Over a 10-year period, a single surgeon treated 486 aneurysms with SAE in which open-cell Neuroform or closed-cell Enterprise stents were used. Single stents were used in 386 cases, overlapping stents were deployed in 80 cases, and Y-configuration stents were used in the remaining 20 cases. All neurological complications, which included transient deficits, were analyzed; disabling strokes and death were considered major complications. The chi-square test and multivariate logistic regression were used to evaluate the influence of aneurysm size and morphology, aneurysm location, stent selection, and stent configuration on complication rates.
\end{abstract}

RESULTS There were 7 deaths (1.4\%), 9 major strokes (1.9\%), and 18 minor neurological complications (3.7\%). For all complications, multivariate analysis revealed that large aneurysm size $(10-25 \mathrm{~mm} ; p=0.01)$, giant aneurysm size $(>25$ $\mathrm{mm} ; \mathrm{p}=0.04)$, fusiform aneurysm morphology $(p=0.03)$, and using a Y-configuration stent $(p=0.048)$ were independent risk factors. For the major complications, independent risk factors included an aneurysm in the posterior circulation ( $p=$ $0.02)$, using an overlapping stent configuration $(p=0.03)$, and using a Y-configuration stent $(p<0.01)$.

CONCLUSIONS In this series, SAE for cerebral aneurysm treatment carried an acceptable complication rate. With continued innovations in techniques and devices and with increased experience, the complication rates associated with SAE may be even lower in the future.

http://thejns.org/doi/abs/10.3171/2014.10.JNS141361

KEY WORDS aneurysm; endovascular; Enterprise; Neuroform; stent; Y stent; vascular disorders

I N 2002, the results of the International Subarachnoid Aneurysm Trial (commonly known as ISAT) suggested that endovascular coiling may provide a minimally invasive, effective, and safe treatment of intracranial aneurysms..$^{22}$ Successful and durable coiling is influenced greatly by aneurysm morphology, particularly the size of the aneurysm neck. ${ }^{24,29}$ Attempts to coil a wide-necked intracranial aneurysm often lead to instability and/or migration of the coil mass with resultant coil protrusion into the parent vessel and possible thromboembolic complications. Moret et al..$^{23}$ have described a balloon remodeling technique, which was intended to improve the placement of coils and to enhance their stability within the aneurysm sac.

Balloon remodeling techniques soon evolved to include the use of stents in stent-assisted embolization (SAE). ${ }^{21,31}$ Initially, cardiac stents were used, but they proved too rigid to be navigated safely through the tortuous and thinwalled cerebral vasculatures. ${ }^{20}$ Therefore, SAE was limited to proximal aneurysms until the development of the Neuroform stent (Stryker Neurovascular), a flexible, opencell, self-expanding stent made of nitinol. ${ }^{10,15}$ Development

ABBREVIATIONS DSA = digital subtraction angiography; MRA = MR angiography; OR = odds ratio; SAE = stent-assisted embolization; $S A S N=$ small aneurysm, small neck; SAWN = small aneurysm, wide neck.

SUBMITTED June 17, 2014. ACCEPTED October 30, 2014.

INCLUDE WHEN CITING Published online May 15, 2015; DOI: 10.3171/2014.10.JNS141361.

DISCLOSURE Dr. Johnson is a cofounder of Gaudi Vascular, Inc.; Dr. Lopes has financial and research relationships with Penumbra, eV3, and Stryker. Drs. Munich, Tan, Heiferman, and Ms. Keigher have no financial disclosures. The authors report no conflict of interest concerning the materials or methods used in this study or the findings specified in this paper. 
of the closed-cell Enterprise stent (Cordis Neurovascular) followed. ${ }^{14}$ Both the Neuroform and the Enterprise stents have made endovascular treatment of wide-necked aneurysms feasible; furthermore, they have allowed tighter coil packing and increased stability of the coil mass, which increased the effectiveness of embolization and decreased recurrence rates. ${ }^{27}$ More recently, the development of flowdiverting stents enabled purely endoluminal treatment of intracranial aneurysms without the need of introducing embolic materials into the aneurysm sac. ${ }^{25}$ The implementation of self-expanding nitinol (e.g., Neuroform and Enterprise) stents has broadened the scope of endovascular treatment to increasingly complex aneurysms. Complex stent configurations, including Y configurations, have been used to treat aneurysms located at bifurcations and aneurysms with necks that incorporate significant portions of both daughter vessels. ${ }^{18,30}$ Overlapping stent arrangements have been used to bridge aneurysms with fusiform morphology and very wide necks to reinforce inadequate single stents and to enhance flow diversion., ${ }^{1,33}$ Despite the improved vessel reconstruction, potential complications with multistent constructs remain a topic of great interest to neurointerventional surgeons. In this study, complications in a series of 486 aneurysms treated with SAE by a single surgeon over a 10 -year time span were analyzed to better understand the risk factors associated with SAE.

\section{Methods \\ Patients}

Self-expanding nitinol stents were used to treat 486 aneurysms in 422 patients between October 2002 and January 2012. The senior author (D.K.L.) performed each procedure, and this period represents his initial decade of experience with SAE. Each patient was provided the options of endovascular repair with possible stent placement, microsurgery, and observation for management of the aneurysm. Each patient signed informed research consent before stent placement as part of the Rush University Medical Center's institutional review board protocol. Patients were enrolled in the study prospectively. Women harbored 362 (74.5\%) of the aneurysms. The average patient age was 58.2 years (range 19-86 years; SD 12.8 years).

\section{Aneurysms}

Characteristics of the treated aneurysms are provided in Table 1. Aneurysms were classified as small, large, or giant if their maximal diameter was $<10,10-25$, or $>25$ $\mathrm{mm}$, respectively. Fusiform aneurysms were defined as those in which the vessel was circumferentially involved. An aneurysm was considered to have a wide neck if the size of the neck was $>4 \mathrm{~mm}$ or if the dome-to-neck ratio was $<1$. Twelve $(2.5 \%)$ of the stented aneurysms had acutely ruptured, whereas $11(2.3 \%)$ were coiled after initial rupture and then stented in a delayed, staged fashion.

\section{Stents and Stent Configurations}

Open-cell Neuroform stents (Stryker Neurovascular) were used beginning in 2002, and closed-cell Enterprise stents (Cordis Neurovascular) were used beginning in 2007. A Wingspan stent was used in 1 aneurysm with
TABLE 1. Aneurysm characteristics

\begin{tabular}{ccc}
\hline Characteristic & No. of Cases & $\%$ \\
\hline Size & & \\
\hline Small $(<10 \mathrm{~mm})$ & 356 & 73.3 \\
\hline SASN & 158 & 32.5 \\
\hline SAWN & 198 & 40.7 \\
\hline Large $(10-25 \mathrm{~mm})$ & 85 & 17.5 \\
\hline Giant $(>25 \mathrm{~mm})$ & 13 & 2.7 \\
\hline Fusiform & 32 & 6.6 \\
\hline Location & & \\
\hline Anterior circulation & 407 & 83.7 \\
\hline Posterior circulation & 79 & 16.3 \\
\hline Rupture status & & \\
\hline Unruptured & 463 & 2.5 \\
\hline Acutely ruptured & 12 & 2.3 \\
\hline Subacute rupture & 11 &
\end{tabular}

associated intracranial stenosis, and this aneurysm was included in the open-cell Neuroform group for statistical analysis purposes. Stent selection and configuration were determined by the angiographic details of the aneurysm and the known advantages and limitations of each stent design available at the time of treatment. ${ }^{2,28}$ Stent-selection and configuration details are listed in Table 2.

\section{Antiplatelet Strategy}

Preoperative management for patients with an unruptured aneurysm included dual antiplatelet therapy with aspirin (325 mg) and clopidogrel (75 mg) daily for 5 days before stent placement. Patients unable to complete this regimen were loaded with $600 \mathrm{mg}$ of clopidogrel and 325 mg of aspirin before the procedure. Antiplatelet activity was measured by using point-of-care VerifyNow (Accumetrics) aspirin and P2Y12 platelet function assays. For patients with a ruptured aneurysm and for those in whom antiplatelet therapy was not therapeutic (i.e., $>550$ aspirin reaction units or $>230 \mathrm{P} 2 \mathrm{Y} 12$ reaction units), an intraarterial loading dose of $0.25 \mathrm{mg} / \mathrm{kg}$ abciximab $(0.25 \mathrm{mg} / \mathrm{kg})$ was given at the time of stent placement followed by a 12 -hour infusion $(0.125 \mu \mathrm{g} / \mathrm{kg} / \mathrm{min}$ or $10 \mu \mathrm{g} / \mathrm{min})$. Abciximab was also given if thrombus developed inside of the stent or if the patient had a new neurological deficit after treatment and head CT revealed no hemorrhage. Patients with a single-stent configuration were continued on dual antiplatelet therapy for 3 months. Patients with multiple stents were kept on dual antiplatelet therapy for 6 months and aspirin for $\geq 1$ year.

TABLE 2. Stent configurations and types

\begin{tabular}{lrrrr}
\hline & \multicolumn{4}{c}{ No. of Stents } \\
\cline { 2 - 5 } Stent Configuration & Neuroform & Enterprise & Mixed & Total \\
\hline Single & 296 & 90 & 0 & 386 \\
\hline Overlapping & 32 & 18 & 30 & 80 \\
\hline Y & 8 & 3 & 9 & 20 \\
\hline Total & 336 & 111 & 39 & 486 \\
\hline
\end{tabular}




\section{Procedures}

The typical procedure was performed with the patient under general anesthesia with continuous neurological monitoring using somatosensory evoked potentials and electroencephalography. After femoral access was obtained, the patient was given a heparin bolus of $100 \mathrm{U} / \mathrm{kg}$, and the activated clotting time was maintained at $>250$ seconds. The preferred SAE technique was stenting followed by coiling through the stent struts.

\section{Radiographic Assessment}

Immediate posttreatment digital subtraction angiography (DSA) was performed to assess aneurysm occlusion, and follow-up DSA was performed at 6 months. Longterm imaging follow-up typically was performed with MRI and MR angiography (MRA) beginning 1 year after treatment. Thereafter, MRI and MRA were repeated yearly. CT angiography and/or DynaCT (Siemens) was used in patients unable to undergo MRI and MRA. Aneurysms with either residual filling of $>2-3 \mathrm{~mm}$ or with growth of known residual were scheduled for DSA with possible re-treatment. After re-treatment, the follow-up process started again with angiography at 6 months. Re-treatment rates and angiographic results are considered in a separate ongoing study.

\section{Complications}

Complications were categorized as transient, minor, major, or death. Transient neurological complications resolved entirely before hospital discharge. Minor complications were nondisabling strokes that resolved within 30 days of hospital discharge. Major complications included permanent disabling neurological events. Death was considered separately but included in the analysis of major complications. For patients with multiple complications, their aneurysm was categorized according to their worst complication.

Every complication was analyzed for association with aneurysm size and morphology, aneurysm location, stent type, and stent configuration. All the complications that could be attributed to the stenting procedure or the treated aneurysm were included and are presented herein.

\section{Statistical Analysis}

Both the chi-square test and multivariate logistic regression were used to identify statistically significant risk factors. For aneurysm size and morphology, the subcategories included small aneurysm, small neck (SASN), small aneurysm, wide neck (SAWN), large, giant, and fusiform. Anterior and posterior circulation locations were considered. Stent types included Neuroform and Enterprise. Configurations included single stent, overlapping stents, and Y-configuration stents. The SASN, anterior circulation, and single-Neuroform-stent groups were used as references for odds ratio (OR) calculations of total and major complications for size, location, and stent configuration, respectively.

A separate multivariate logistic regression analysis was performed to compare the ORs of different stent configurations (single vs overlapping vs Y). In this case, the single-stent group, including Neuroform and Enterprise stents, was used as the reference for OR calculations; the overlapping-stents group included Neuroform, Enterprise, and mixed-type stents. All statistical analyses were performed using SPSS version 19 (IBM Corp). Significance was determined by a $\mathrm{p}$ value of $<0.05$.

\section{Results \\ Total Complications}

Included in the study were 486 original stenting procedures, 52 re-treatment procedures (in 45 patients), and 421 follow-up diagnostic angiograms. During a mean followup time of 1.89 years after initial SAE, there were 57 neurological complications (11.7\%), including 7 deaths (1.4\%), 9 major strokes (1.9\%), 18 minor complications (3.7\%), and 23 transient complications $(4.7 \%)$.

Twenty-eight (5.8\%) complications, including 7 major strokes (1.4\%) and 5 deaths (1.0\%), occurred within 24 hours of treatment; 2 of these deaths were secondary to hemorrhage, whereas the other deaths and major strokes were ischemic in nature. Two patients had a giant aneurysm that ruptured within 2 weeks of stent placement, and 1 of these patients died. One patient died after a hemorrhage following repeat treatment with coils only. Timing of the complications that occurred during the follow-up period is shown in Fig. 1. The only major complication beyond 1 year was an ischemic stroke that occurred 371 days after treatment with overlapping stents in a patient with a small posterior communicating artery aneurysm.

Forty-four nonneurological complications occurred during the study period. There were 31 groin complications, including 5 femoral pseudoaneurysms, 9 retroperitoneal hematomas, and 1 fistula. Surgical intervention was successful in the treatment of 2 ischemic limbs. There were 8 systemic bleeding complications; 4 gastrointestinal, 2 epistaxis, 1 vaginal, and 1 related to a radial arterial line. One of the gastrointestinal bleeds forced the discontinuation of antiplatelet therapy and resulted in a procedure-related death, which was included in the complication analysis. The remaining nonneurological complications included significant occipital hair loss in 1 patient and 4 minor anesthesia-related complications.

\section{Aneurysm Size and Morphology}

Among 356 small aneurysms, there were 30 complications $(8.4 \%)$, of which $6(1.7 \%)$ were major. There were no significant differences in total or major complications in small aneurysms with small necks and those with wide necks. Of the 85 large aneurysms, there were 16 total complications (18.8\%), 4 (4.7\%) of which were major. Thirteen giant aneurysms had 4 total $(30.8 \%)$ and 2 major (15.4\%) complications; the 32 fusiform aneurysms had 7 total $(21.9 \%)$ and 4 major $(12.5 \%)$ complications. The chi-square test revealed higher total complication rates in large (OR 3.43; $\mathrm{p}=0.004)$, giant (OR 6.58; $\mathrm{p}=0.006)$, and fusiform (OR 4.14; $\mathrm{p}=0.008)$ aneurysms, and these results were confirmed in the multivariate analysis. Major complication rate disparities were not statistically significant with respect to aneurysm size or morphology in the multivariate analysis. ORs from the multivariate analyses 


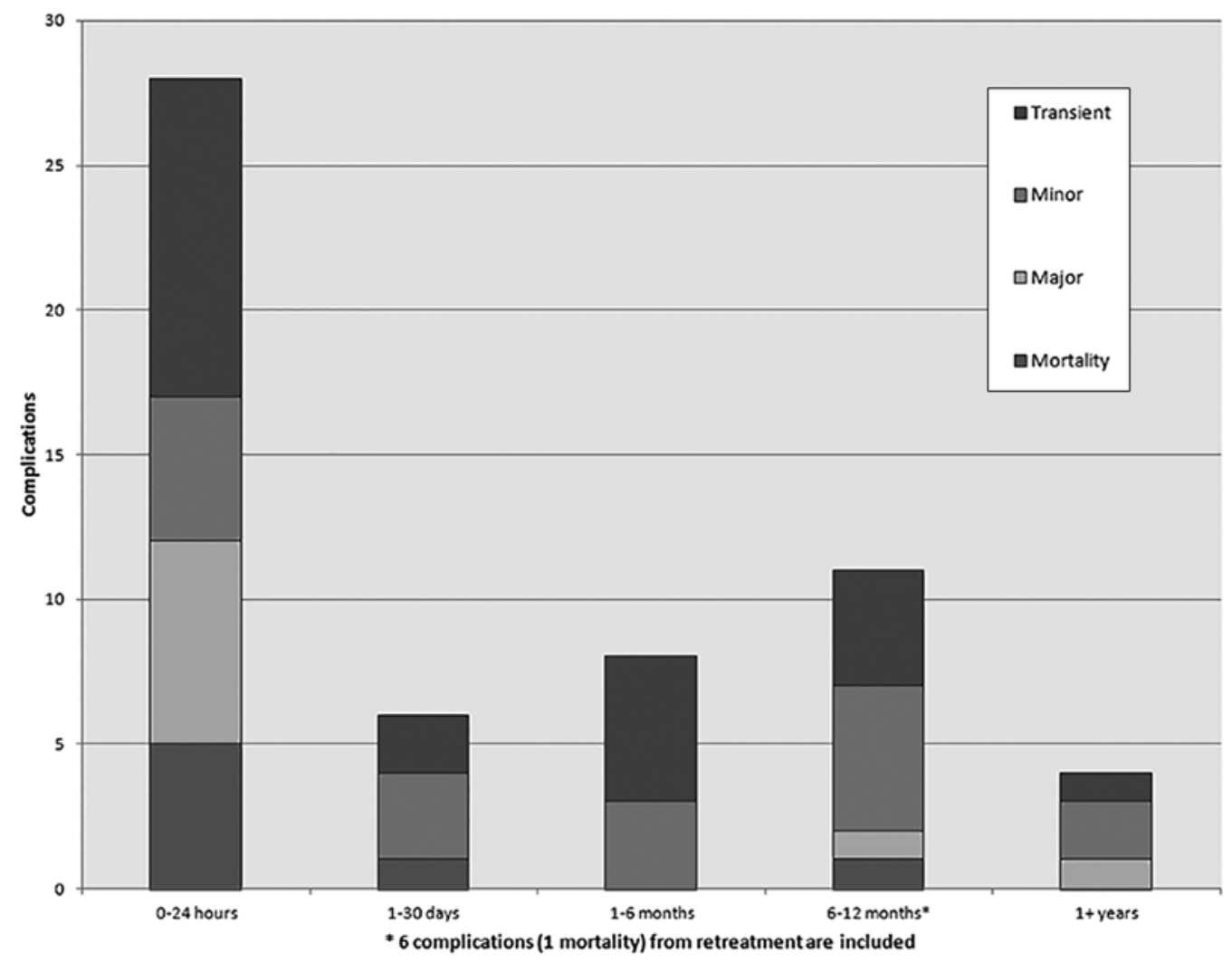

FIG. 1. Timing of complications that occurred during the follow-up period.

for all complications and the major ones are summarized in Tables 3 and 4, respectively.

\section{Location}

Among 407 anterior circulation aneurysms, there were 47 total $(11.5 \%)$ and 8 major (2.0\%) complications. There was not an increased risk in total complications (10 of 79 [12.7\%]) with posterior circulation aneurysms; however, complications in the patients with a posterior circulation aneurysm tended to be worse, with $8(10.1 \%)$ being major complications (significant in the univariate [OR 5.62; $\mathrm{p}=$ $0.001]$ and multivariate analyses [Table 4]).

\section{Stent Type}

There were no significant differences in either total or major complication rates between open-cell (Neuroform) and closed-cell (Enterprise) stent use. For each stent type, the complication rate was higher for overlapping-stent treatments than for single-stent treatments. Aneurysms treated with overlapping constructs that included at least 1 open-cell stent fared worse than those treated with overlapping closed-cell stents; however, results of a comparison of major complications in these 2 groups did not reach statistical significance (OR 2.33; $\mathrm{p}=0.44)$.

\section{Stent Configuration}

A single-stent configuration was used in the treatment of 386 aneurysms; there were 35 total complications (9.1\%) and 5 major complications (1.3\%). Overlapping stents were placed across 80 aneurysms; there were
17 total complications $(21.3 \%), 8(10.0 \%)$ of which were major. Y-configuration stenting was used in the treatment of 20 aneurysms; there were 5 total complications (25\%), 3 of which (15\%) were major. The ORs for all and major complications for different stent configurations (all singlestent constructs were considered together and used as the reference group) were calculated in a separate multivariate analysis, the results of which are summarized in Tables 5 and 6, respectively. Overlapping (OR 2.56; $\mathrm{p}<0.01$ ) and Y-configuration (OR 3.17; $\mathrm{p}=0.03$ ) stent constructs increased the total complication risk over that of single-stent constructs on chi-square analysis; multivariate analysis revealed that Y-configuration stenting was an independent risk factor for total complications (Table 5). Multivariate analysis revealed that both overlapping and Y-configuration constructs were independent risk factors for major complications (Table 6).

\section{Discussion}

With the introduction of SAE, aneurysms that would have otherwise required extensive open surgical treatment may now be treated through an effective and minimally invasive approach. Although the long-term durability of SAE has been suggested previously, ${ }^{6,11,16}$ there have been fewer reports on the complications associated with this intervention. ${ }^{4,13,28,34}$ In the present study, the overall complication rate was $11.7 \%$, whereas the major, permanent morbidity/mortality rate was 3.3\%. In a recent publication regarding long-term follow-up for a similarly sized series of patients who underwent SAE, Jahshan et al. ${ }^{16}$ found a 
TABLE 3. Multivariate analysis of all complications

\begin{tabular}{lcccc}
\hline & & \multicolumn{2}{c}{$95 \% \mathrm{Cl}$} & \\
\cline { 3 - 4 } Aneurysm Characteristic & OR & Lower & Upper & p Value \\
\hline Size & & & & \\
\hline Small & & & & \\
\hline SASN & 1.00 & - & - & - \\
\hline SAWN & 1.73 & 0.78 & 3.86 & 0.18 \\
\hline Large & 3.24 & 1.34 & 7.83 & 0.01 \\
\hline Giant & 4.73 & 1.11 & 20.17 & 0.04 \\
\hline Fusiform & 3.65 & 1.11 & 11.99 & 0.03 \\
\hline Location & & & & \\
\hline Anterior circulation & 1.00 & - & - & - \\
\hline Posterior circulation & 0.71 & 0.31 & 1.62 & 0.41 \\
\hline Stent configuration & & & & \\
\hline Single & & & & \\
\hline Neuroform & 1.00 & - & - & - \\
\hline Enterprise & 1.72 & 0.78 & 3.76 & 0.18 \\
\hline Overlapping & & & & \\
\hline Neuroform & 1.78 & 0.63 & 5.02 & 0.28 \\
\hline Enterprise & 1.74 & 0.44 & 6.94 & 0.43 \\
\hline Mixed & 3.18 & 1.16 & 8.68 & 0.02 \\
\hline Y & 3.47 & 1.12 & 10.71 & 0.03 \\
\hline
\end{tabular}

permanent event-related morbidity rate of $4.3 \%$ in 489 cases. Only 2 major complications occurred $>6$ months after the most recent treatment. Complication analysis in our series revealed that a posterior circulation location and a multistent construct were independent risk factors for major complications.

TABLE 4. Multivariate analysis of major complications

\begin{tabular}{lcccc}
\hline & & \multicolumn{2}{c}{$95 \% \mathrm{Cl}$} & \\
\cline { 3 - 4 } Aneurysm Characteristic & OR & Lower & Upper & p Value \\
\hline Size & & & & \\
\hline Small & & & & \\
\hline SASN & 1.00 & - & - & - \\
\hline SAWN & 0.59 & 0.11 & 3.11 & 0.53 \\
\hline Large & 0.92 & 0.17 & 5.02 & 0.92 \\
\hline Giant & 4.23 & 0.50 & 35.82 & 0.19 \\
\hline Fusiform & 2.03 & 0.30 & 13.60 & 0.47 \\
\hline Location & & & & \\
\hline Anterior circulation & 1.00 & - & - & - \\
\hline Posterior circulation & 4.08 & 1.22 & 13.61 & 0.02 \\
\hline Stent configuration & & & & \\
\hline Single & & & & \\
\hline Neuroform & 1.00 & - & - & - \\
\hline Enterprise & 0.59 & 0.06 & 5.73 & 0.65 \\
\hline Overlapping & & & & \\
\hline Neuroform & 4.78 & 0.90 & 25.52 & 0.07 \\
\hline Enterprise & 1.50 & 0.13 & 17.13 & 0.74 \\
\hline Mixed & 4.98 & 0.86 & 28.90 & 0.07 \\
\hline Y & 10.27 & 1.89 & 55.84 & 0.01 \\
\hline
\end{tabular}

TABLE 5. Multivariate analysis of all complications

\begin{tabular}{ccccc}
\hline & & \multicolumn{2}{c}{$95 \% \mathrm{Cl}$} & \\
\cline { 3 - 4 } Stent Configuration & OR & Lower & Upper & p Value \\
\hline Single* $^{*}$ & 1.00 & - & - & - \\
\hline Overlapping $^{*}$ & 1.90 & 0.93 & 3.90 & 0.079 \\
\hline$Y$ & 3.05 & 1.01 & 9.22 & 0.048 \\
\hline
\end{tabular}

* SAE procedures performed on SASN and SAWN lesions were analyzed in a single group.

\section{Aneurysm Size and Morphology}

Larger aneurysms were associated with more total complications and trended toward having more major complications. Consistent with the literature regarding all treatment modalities, giant and fusiform aneurysms were more dangerous to treat when nitinol stents were used. When the anatomy permits, flow-diverting stents may be the best modality for treating these challenging aneurysms. The Matrix and Platinum Science (MAPS) trial examined aneurysm neck sizes and found a neck diameter of $>4 \mathrm{~mm}$ to be an independent risk factor for complications. ${ }^{26}$ For small aneurysms in our series, there was no significant difference in complications between the small- and widenecked aneurysm groups; furthermore, there were fewer major complications in the wide-necked aneurysm group.

\section{Location}

Aneurysms in the posterior circulation are often more difficult to treat with various modalities, including clipping, ${ }^{9}$ coiling, ${ }^{19}$ and stent-assisted coiling. ${ }^{4}$ Posterior circulation aneurysm treatment in our study resulted in an overall complication rate that was comparable to that of anterior circulation aneurysms; however, the complications in the posterior circulation were more severe. This vascular territory is eloquent and generally filled with vulnerable perforating arteries that supply the brainstem; therefore, procedures performed in this area result in a morbidity rate that is higher than that after procedures performed in areas with fewer perforators.

\section{Stent Type}

No significant difference was seen in complication risks after placing either of the 2 stent types used in the series (Neuroform and Enterprise). The similarly sized series of Chalouhi et al. ${ }^{4}$ also revealed no difference in risk between Neuroform and Enterprise use. However, the data suggested that closed-cell stents may be safer than opencell stents when an overlapping-stent construct is used.

TABLE 6. Multivariate analysis of major complications

\begin{tabular}{ccccc}
\hline & & \multicolumn{2}{c}{$95 \% \mathrm{Cl}$} & \\
\cline { 3 - 4 } Stent Configuration & OR & Lower & Upper & p Value \\
\hline Single* & 1.00 & - & - & - \\
\hline Overlapping & 4.43 & 1.19 & 16.50 & 0.027 \\
\hline$Y$ & 11.43 & 2.20 & 59.27 & 0.004 \\
\hline
\end{tabular}

* SAE procedures performed on SASN and SAWN lesions were analyzed in a single group. 


\section{Stent Configuration}

Multiple-stent constructs have been found to induce greater alteration in flow and intraaneurysmal hemodynamics, which result in more reliable thrombosis. ${ }^{17,33}$ The overlapping, telescoping, or "stent-in-stent" technique for aneurysm treatment is widely used, generally for more complex, giant, and/or fusiform aneurysms, but the risk conveyed by additional stents has not yet been defined. Apposition of the second stent to the vessel wall may be limited by the first stent. Furthermore, overlapping stents may increase the risk of perforator occlusion, and the greater number of intraluminal stent struts may increase thromboembolic risk. Results from several smaller series have suggested efficacy and safety with the use of overlapping-stent constructs. ${ }^{3,8,30}$ Chalouhi et al. ${ }^{4}$ reported no complications in 28 patients with overlapping stents. Our study may include the largest series of overlapping-stent treatments for aneurysms. With all stent types included in the analysis, an overlapping-stent configuration was a statistically significant independent risk factor for major complications in 80 treated aneurysms.

There has been considerable enthusiasm for Y-configuration stenting since its description a decade ago. Reports from several small series described good results, but few reports from larger series have been published. Y-configuration stenting places the tines of both stents in the lumen of the vessel bifurcation in an unpredictable fashion as 1 stent is opened through a single cell of the other. Furthermore, friction may occur as 1 stent is pulled through the struts of the other, resulting in stress on the cerebral vasculature and predisposing it to vessel perforation. ${ }^{1}$ Fargen et al. ${ }^{8}$ combined the single-center experiences of 7 institutions and found that among 45 patients treated with Y-configuration stenting, 3 (7.5\%) of 40 had a modified Rankin Scale score of $\geq 3$ at follow-up. Spiotta et al. ${ }^{30}$ reported 4 clinically significant strokes in a series of 19 patients with Y-stented aneurysms, $3(15.8 \%)$ of which seemed to be major complications. Chalouhi et al..$^{5}$ reported 1 significant complication $(6.3 \%)$ in 16 basilar tip aneurysms treated with Y-configuration stenting. Heller et al..$^{12}$ reported 16 cases in which Y-configuration stenting was used without complications or restricted diffusion seen in follow-up MRI. Results from our series suggest that Y-configuration stenting is an independent risk factor when compared with single SAE. Nonoverlapping Y-configuration stenting may be a safer alternative to standard Y-configuration stenting.?

\section{Limitations}

There were several limitations in this retrospective single-center series. First, there are different indications for each stent type, and stent selection was not randomized. Furthermore, there was no true control group in the study. A limited number of factors were considered in the complication analysis, and some risk factors that other authors have found were not analyzed. For example, fusiform aneurysms are tremendously heterogeneous. Perhaps most important is that analyses of factors that influenced the choice of configuration were not tracked, particularly with respect to technical complications with assisted single-stent embolization, which may have led to overlapping constructs. Thus, some single-stent complications may have been falsely attributed to the overlapping-construct group.

Stent-selection criteria were not uniform because Neuroform stents were introduced into practice before Enterprise stents. The Enterprise-stent group may have had advantageous selection criteria, whereas the Neuroform stent was required for all cases before the availability of the other stents, including those in which overlapping stents were required. The learning curve for stenting may have been steepest for Neuroform stenting because of its early introduction.

\section{Future SAE}

Stents have become increasingly tailored to treat different types of intracranial aneurysms. Advances in stent delivery and options for stent size and porosity, including flow diverters, have decreased the need for complex stent configurations. This series provides an example of technological progress in the embolization of many large, giant, and fusiform aneurysms, which was more challenging when first-generation self-expanding nitinol stents were used. As aneurysm-embolization technology continues to evolve, it will provide more precise, safer, and durable treatment for patients with intracranial aneurysms.

\section{Conclusions}

This series illustrates the progression of SAE of aneurysms over the last decade. There has been significant refinement of SAE as a consequence of new technology and techniques. The complication rate seen in this early experience is likely to decrease in the future with further tailoring of stents and flow diverters to specific aneurysm characteristics.

\section{References}

1. Ansari SA, Lassig JP, Nicol E, Thompson BG, Gemmete JJ, Gandhi D: Thrombosis of a fusiform intracranial aneurysm induced by overlapping neuroform stents: Case report. Neurosurgery 60:E950-E951, 2007

2. Bain M, Hussain MS, Spiotta A, Gonugunta V, Moskowitz S, Gupta R: "Double-barrel" stent reconstruction of a symptomatic fusiform basilar artery aneurysm: case report. Neurosurgery 68:E1491-E1496, 2011

3. Chalouhi N, Campbell P, Makke Y, Yadla S, Dumont AS, Gonzalez LF, et al: Treatment of complex intracranial aneurysms with a telescoping stent technique. J Neurol Surg A Cent Eur Neurosurg 73:281-288, 2012

4. Chalouhi N, Drueding R, Starke RM, Jabbour P, Dumont AS, Gonzalez LF, et al: In-stent stenosis after stent-assisted coiling: incidence, predictors and clinical outcomes of 435 cases. Neurosurgery 72:390-396, 2013

5. Chalouhi N, Jabbour P, Gonzalez LF, Dumont AS, Rosenwasser R, Starke RM, et al: Safety and efficacy of endovascular treatment of basilar tip aneurysms by coiling with and without stent assistance: a review of 235 cases. Neurosurgery 71:785-794, 2012

6. Chalouhi N, Jabbour P, Singhal S, Drueding R, Starke RM, Dalyai RT, et al: Stent-assisted coiling of intracranial aneurysms: predictors of complications, recanalization, and outcome in 508 cases. Stroke 44:1348-1353, 2013

7. Cho YD, Park SW, Lee JY, Seo JH, Kang HS, Kim JE, et al: Nonoverlapping Y-configuration stenting technique with dual closed-cell stents in wide-neck basilar tip aneurysms. Neurosurgery 70 (2 Suppl Operative):244-249, 2012 
8. Fargen KM, Mocco J, Neal D, Dewan MC, Reavey-Cantwell J, Woo HH, et al: A multicenter study of stent-assisted coiling of cerebral aneurysms with a Y configuration. Neurosurgery 73:466-472, 2013

9. Ferns SP, Sprengers ME, van Rooij WJ, Rinkel GJ, van Rijn JC, Bipat S, et al: Coiling of intracranial aneurysms: a systematic review on initial occlusion and reopening and retreatment rates. Stroke 40:e523-e529, 2009

10. Fiorella D, Albuquerque FC, Han P, McDougall CG: Strategies for the management of intraprocedural thromboembolic complications with abciximab (ReoPro). Neurosurgery 54:1089-1098, 2004

11. Galal A, Bahrassa F, Dalfino JC, Boulos AS: Stent-assisted treatment of unruptured and ruptured intracranial aneurysms: clinical and angiographic outcome. Br J Neurosurg 27:607-616, 2013

12. Heller RS, Dandamudi V, Calnan D, Malek AM: Neuroform intracranial stenting for aneurysms using simple and multistent technique is associated with low risk of magnetic resonance diffusion-weighted imaging lesions. Neurosurgery 73:582-591, 2013

13. Hetts SW, Turk A, English JD, Dowd CF, Mocco J, Prestigiacomo C, et al: Stent-assisted coiling versus coiling alone in unruptured intracranial aneurysms in the matrix and platinum science trial: Safety, efficacy, and mid-term outcomes. AJNR Am J Neuroradiol, 2014

14. Higashida RT, Halbach VV, Dowd CF, Juravsky L, Meagher $\mathrm{S}$ : Initial clinical experience with a new self-expanding nitinol stent for the treatment of intracranial cerebral aneurysms: the Cordis Enterprise stent. AJNR Am J Neuroradiol 26:1751-1756, 2005

15. Howington JU, Hanel RA, Harrigan MR, Levy EI, Guterman LR, Hopkins LN: The Neuroform stent, the first microcatheter-delivered stent for use in the intracranial circulation. Neurosurgery 54:2-5, 2004

16. Jahshan S, Abla AA, Natarajan SK, Drummond PS, Kan P, Karmon Y, et al: Results of stent-assisted vs non-stent-assisted endovascular therapies in 489 cerebral aneurysms: singlecenter experience. Neurosurgery 72:232-239, 2013

17. Jeon P, Kim BM, Kim DI, Park SI, Kim KH, Kim DJ, et al: Reconstructive endovascular treatment of fusiform or ultrawide-neck circumferential aneurysms with multiple overlapping enterprise stents and coiling. AJNR Am J Neuroradiol 33:965-971, 2012

18. Johnson AK, Heiferman DM, Lopes DK: Stent-assisted embolization of 100 middle cerebral artery aneurysms. J Neurosurg 118:950-955, 2013

19. Kim M, Levy EI, Meng H, Hopkins LN: Quantification of hemodynamic changes induced by virtual placement of multiple stents across a wide-necked basilar trunk aneurysm. Neurosurgery 61:1305-1313, 2007

20. Lanzino G, Wakhloo AK, Fessler RD, Hartney ML, Guterman LR, Hopkins LN: Efficacy and current limitations of intravascular stents for intracranial internal carotid, vertebral, and basilar artery aneurysms. J Neurosurg 91:538-546, 1999

21. Mericle RA, Lanzino G, Wakhloo AK, Guterman LR, Hopkins LN: Stenting and secondary coiling of intracranial internal carotid artery aneurysm: technical case report. Neurosurgery 43:1229-1234, 1998

22. Molyneux A, Kerr R, Stratton I, Sandercock P, Clarke M, Shrimpton J, et al: International Subarachnoid Aneurysm Trial (ISAT) of neurosurgical clipping versus endovascular coiling in 2143 patients with ruptured intracranial aneurysms: a randomized trial. J Stroke Cerebrovasc Dis 11:304-314, 2002

23. Moret J, Cognard C, Weill A, Castaings L, Rey A: The "remodelling technique" in the treatment of wide neck intracranial aneurysms. Angiographic results and clinical follow-up in 56 cases. Interv Neuroradiol 3:21-35, 1997

24. Murayama Y, Nien YL, Duckwiler G, Gobin YP, Jahan R, Frazee J, et al: Guglielmi detachable coil embolization of cerebral aneurysms: 11 years' experience. J Neurosurg 98:959-966, 2003

25. Nelson PK, Lylyk P, Szikora I, Wetzel SG, Wanke I, Fiorella $\mathrm{D}$ : The pipeline embolization device for the intracranial treatment of aneurysms trial. AJNR Am J Neuroradiol 32:34-40, 2011

26. Raaymakers TW, Rinkel GJ, Limburg M, Algra A: Mortality and morbidity of surgery for unruptured intracranial aneurysms: a meta-analysis. Stroke 29:1531-1538, 1998

27. Raymond J, Darsaut TE, Bing F, Makoyeva A, Kotowski M, Gevry G, et al: Stent-assisted coiling of bifurcation aneurysms may improve endovascular treatment: a critical evaluation in an experimental model. AJNR Am J Neuroradiol 34:570-576, 2013

28. Saatci I, Geyik S, Yavuz K, Cekirge S: X-configured stent-assisted coiling in the endovascular treatment of complex anterior communicating artery aneurysms: a novel reconstructive technique. AJNR Am J Neuroradiol 32:E113-E117, 2011

29. Songsaeng D, Geibprasert S, ter Brugge KG, Willinsky R, Tymianski M, Krings T: Impact of individual intracranial arterial aneurysm morphology on initial obliteration and recurrence rates of endovascular treatments: a multivariate analysis. J Neurosurg 114:994-1002, 2011

30. Spiotta AM, Gupta R, Fiorella D, Gonugunta V, Lobo B, Rasmussen PA, et al: Mid-term results of endovascular coiling of wide-necked aneurysms using double stents in a Y configuration. Neurosurgery 69:421-429, 2011

31. Szikora I, Guterman LR, Wells KM, Hopkins LN: Combined use of stents and coils to treat experimental wide-necked carotid aneurysms: preliminary results. AJNR Am J Neuroradiol 15:1091-1102, 1994

32. Tan LA, Moftakhar R, Lopes DK: Treatment of a ruptured vertebrobasilar fusiform aneurysm using pipeline embolization device. J Cerebrovasc Endovasc Neurosurg 15:30-33, 2013

33. Tremmel M, Xiang J, Natarajan SK, Hopkins LN, Siddiqui $\mathrm{AH}$, Levy EI, et al: Alteration of intra-aneurysmal hemodynamics for flow diversion using enterprise and vision stents. World Neurosurg 74:306-315, 2010

34. Wang K, Sun Y, Li AM: Peri-procedural morbidity and mortality associated with stent-assisted coiling for intracranial aneurysms. Interv Neuroradiol 19:43-48, 2013

\section{Author Contributions}

Conception and design: Lopes, Johnson. Acquisition of data: all authors. Analysis and interpretation of data: Lopes, Johnson, Munich, Tan. Drafting the article: Lopes, Johnson, Munich, Tan, Heiferman. Critically revising the article: all authors. Reviewed submitted version of manuscript: all authors. Statistical analysis: Tan.

\section{Correspondence}

Demetrius Klee Lopes, Department of Neurosurgery, Rush University Medical Center, 1725 W. Harrison St., Ste. 855, Chicago, IL 60612. email: demetrius_lopes@rush.edu. 